\title{
Management of acquired nonmalignant tracheoesophageal fistula: Surgical pearls
}

\author{
K. Robert Shen, MD
}

\author{
From the Division of General Thoracic Surgery, Department of Surgery, Mayo Clinic, Rochester, Minn. \\ Disclosures: Author has nothing to disclose with regard to commercial support. \\ Received for publication Aug 16, 2017; accepted for publication Aug 18, 2017; available ahead of print Sept 12, \\ 2017. \\ Address for reprints: K. Robert Shen, MD, Division of General Thoracic Surgery, Department of Surgery, Mayo \\ Clinic, 200 First St SW, Rochester, MN 55905 (E-mail: shen.krobert@mayo.edu). \\ J Thorac Cardiovasc Surg 2017;154:e123 \\ $0022-5223 / \$ 36.00$ \\ Copyright (C) 2017 Published by Elsevier Inc. on behalf of The American Association for Thoracic Surgery \\ http://dx.doi.org/10.1016/j.jtcvs.2017.08.031
}

Acquired nonmalignant fistulization between the airway and esophagus is a rare but challenging problem to manage. The 2 most recent single-institution series of patients with tracheoesophageal fistula (TEF) reported on 36 patients in an 18-year interval treated surgically at the Massachusetts General Hospital ${ }^{1}$ and 21 patients in 32 years treated at the Mayo Clinic. ${ }^{2}$ The etiology of these TEFs included complications of mechanical ventilation, complications related to previous tracheal or esophageal surgery, trauma, iatrogenic injuries, caustic ingestion, complications related to previous radiation therapy to the mediastinum, and complications related to tracheal or esophageal stents. Regardless of the etiology, TEFs are a life-threatening condition because of their ongoing tracheobronchial contamination, with resulting pulmonary sepsis and interference with nutrition.

In this issue of the Journal, Jha and Jain ${ }^{3}$ present an "Unusual Case of Tracheoesophageal Fistula Caused by Impacted Denture." Although the etiology of the TEF is somewhat unusual, the management of this patient highlights a number of important surgical pearls important to consider when confronted with a patient with a nonmalignant TEF:

1. There is no role for conservative management. Endoluminal tracheal or esophageal stents may have a limited temporizing role to play in controlling ongoing pulmonary soilage until definitive surgical treatment can be undertaken, but they are unlikely to provide satisfactory definitive management of nonmalignant TEFs. Surgical management can be undertaken with excellent long-term results, and it should be considered the first-line treatment for this problem.

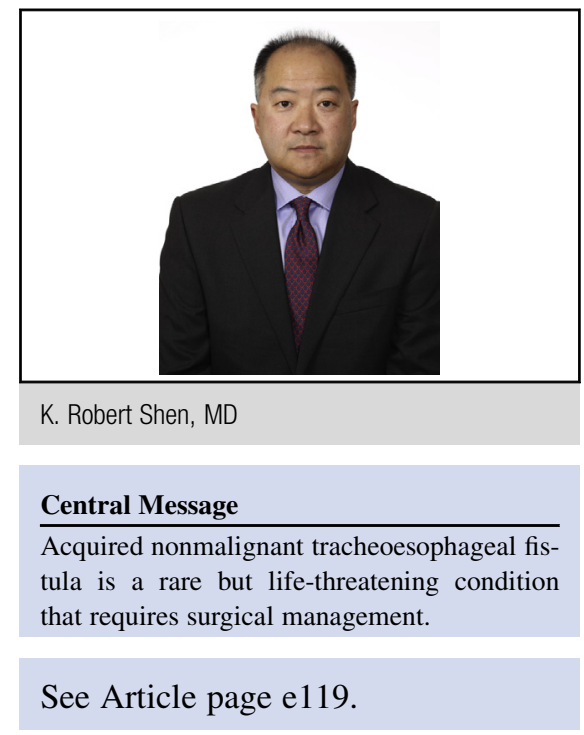

2. Careful optimization of the patient's condition is critical for successful surgical closure of TEFs. This includes weaning patients from mechanical ventilatory support, enteral nutritional support, and control of pulmonary infections before definitive surgical treatment of the TEF.

3. Single-stage primary repair of both airway and esophageal defects is preferred and can safely be performed successfully in most cases of nonmalignant TEF. In patients in whom the etiology of the TEF is postintubation injury, segmental tracheal resection with reconstruction is preferred.

4. Use of vascularized local tissue flaps to buttress the primary repair sites is recommended.

5. Early extubation and avoidance of postoperative positive-pressure ventilation are recommended.

\section{References}

1. Muniappan A, Wain JC, Wright CD, Donahue DM, Gaissert H, Lanuti M, et al Surgical treatment of nonmalignant tracheoesophageal fistula: a thirty-five year experience. Ann Thorac Surg. 2013;95:1141-6.

2. Shen KR, Allen MS, Cassivi SD, Nichols FC III, Wigle DA, Harmsen WS, et al Surgical management of acquired nonmalignant tracheoesophageal and bronchoesophageal fistulae. Ann Thorac Surg. 2010;90:914-8; discussion 919.

3. Jha VK, Jain SK. Unusual case of tracheoesophageal fistula caused by impacted denture. J Thorac Cardiovasc Surg. 2017;154:e119-21. 